\title{
Police Strategies Against Gun Crimes in the United States
}

\author{
Allan Y. Jiao \\ Department of Law \& Justice Studies, Rowan University, Glassboro, USA \\ Email address: \\ jiao@rowan.edu \\ To cite this article: \\ Allan Y. Jiao. Police Strategies Against Gun Crimes in the United States. Humanities and Social Sciences. Vol. 7, No. 1, 2019, pp. 28-33. \\ doi: $10.11648 /$ j.hss.20190701.14 \\ Received: January 14, 2019; Accepted: April 15, 2019; Published: April 28, 2019

\begin{abstract}
To maintain public safety and reduce gun violence, a strong need exists for understanding police strategies, practices, and related issues in addressing gun crimes. As various studies on police handling of gun crimes have been completed and previous reviews of such studies are either outdated or sporadic, it is necessary to conduct a new review of police practices in dealing with gun crimes. This review is focused on police initiatives and practices in the United States including both innovative programs and routine activities that have been studied with various research methods. It is aimed at developing a general understanding of police strategies in terms of their effectiveness in reducing gun crimes.
\end{abstract}

Keywords: Police Strategy, Gun Crime, Effectiveness

\section{Introduction}

Gun crimes are a serious concern to the public and the police across the U.S. Gun crimes range from illegal possession, unlawfully receiving or transferring of a firearm, to violent crimes such as robbery, homicide, and mass shooting. To maintain public safety and reduce gun violence, it is important to understand what have been done, how effective they are, and what need to be done to improve police effectiveness in dealing with gun crimes. Gun crimerelated literature suggests three types of publications, those aimed at understanding characteristics of gun crimes, those examining efficacy of gun-related legislations, and those evaluating effectiveness of police strategies targeting gun crimes. This is a review of studies of police strategies in dealing with gun crimes. Such a review is necessary because previous reviews are either outdated or lacking in comprehensiveness and does not allow a general understanding of what have been done and how effective they are.

This paper includes a review of published articles on police strategies targeting gun crimes. A key-word search was conducted to locate related publications in Criminal Justice Abstract and other online sources. Key words used for the search include "police," "law enforcement", "gun," "firearm," "gun crime," and "risk," resulting in ninety-nine articles with such key words appearing their titles. Upon closer examination, most of these publications do not address police anti-gun strategies and only twenty-six were relevant and selected for review. The review covers the theoretical frameworks, evaluation methods, police strategies, and results of implementing the strategies.

\section{Theoretical Frameworks}

Theories behind various police strategies targeting gun crimes fall generally under problem-oriented policing and situational crime prevention perspective. Problem-oriented policing is based on the idea that finding and addressing the root causes of a certain crime problem are the key to reducing or eliminating it. Problem-oriented policing involves a process of problem identification, analysis, response, evaluation, and adjustment of the response, which has been applied against a wide variety of crime, fear, and disorder concerns [1, 2].

Problem-oriented policing as a theory to reduce gun violence can be applied to places, persons, and risks. Police can focus on reducing the illegal possession, carrying, and use of firearms in gun crime "hot spots" and among violent gun offenders or identifiable risks. Sherman and Rogan [3] suggest three mechanisms through which hot-spots patrol may reduce gun crime in a targeted area: firearms seized in high firearm crime areas may have had significantly higher risk of imminent firearms use in crimes; illegal gun carriers 
who are arrested may be more frequent gun users; and the visibility of the intensive patrols coupled with increased contacts with citizens may deter gun-carrying by those who are not checked by the police. Since a small number of chronic offenders generate a disproportionate share of crime $[4,5]$, focusing police attention on a small number of highrisk gun offenders may be a promising way to control gun violence.

Situational prevention is defined as "opportunity-reducing measures that are (1) directed at highly specific forms of crime (2) that involve the management, design or manipulation of the immediate environment in as systematic and permanent way as possible (3) so as to increase the effort and risks of crime and reduce the rewards as perceived by a wide range of offenders" [6]. The situational perspective is applicable to policing gun crimes because one of its key elements is the specification of "the situational conditions that permit or facilitate the commission of the crimes in question" [6].

Criminal conduct is believed to be "highly susceptible to variations in opportunity and to transitory pressures and inducements" [6]. Studies of the locational dimension of crime, "the spatial and temporal variation in crime patterns," is considered important for discovering "aggregate factors influencing the patterns" [7]. By placing an emphasis on the immediate environment or the situational determinants of crime, police may be able to manage and manipulate these factors to reduce crime [8].

The situational perspective [6] suggests that the immediate environment and organizational activities could influence crimes. Situational variables such as contexts and police operations pertaining to gun incidents may have an effect on gun crime. Police operations defined as routine patrol and investigation activities could explain the results of gun cases that come to their attention. Review of the literature suggests that different locations might be linked to different types and sources of weapons [9-11], different weapons used might account for different crimes committed [12, 13], and how police organize their activities could have an effect on gun crimes $[14,15]$.

\section{Evaluation Methods}

Evaluation methods used to study police gun-crime strategies include time-series design, quasi-experiment, casefile analysis, survey, and descriptive analysis. A basic onegroup time-series design was used to measure the effects of the police strategies on youth gun violence. A quasiexperiment in the form of a pre-post design has often been used to determine the effects of police strategies on firearmrelated crime. For example, one study compared the target areas with a comparison area. Another evaluation used a repeated-differences model. Shots-fired calls for service and firearm-related injuries in two treatment districts were compared with those in the remaining police districts. A certain period served as the pre-period, and another timeframe was used as the post-period [14].

Quasi-experiments rest on the assumptions that the comparison group is in fact comparable [16] and the most critical difference between the targeted and control areas is the police intervention. However, in most studies, the target areas were not chosen randomly and were not identical to the comparison areas. The interventions were of limited duration and scope, focusing on particular areas at particular points in time. As such, the evaluations may not provide insight into long-term effect of police strategies.

Other methods include case-file analysis, survey, and description. Case-file analysis involves the creation of a guncase database using gun case files and analysis of the database to understand the effects of related police activities. However, such databases are extremely rare and statistical analyses of such databases remain at an explorative stage. A survey was conducted that involves sampling police agencies serving cities of 100,000 or more people. Anti-gun police studies are mostly descriptive in nature. Many police strategies such as the aggressive gun-oriented policing strategies of the NYPD have not been formally evaluated [17].

\section{Police Strategies and Implementation Results}

Police strategies designed to address gun violence have been implemented in various metropolitan areas (See Table 1). Program titles include Operation Ceasefire, Project Exile, Project Safe Neighborhoods, Project Felon, Project Triggerlock, and so forth [18]. Most strategies are based on the problem-oriented policing concept or its variations, with community-oriented policing elements, and very few on the situational prevention perspective and routine activity concept. Problem-oriented policing strategies include placeoriented strategies, directed/targeted patrol, hot-spot policing, gun suppression, and gang- or offender-based suppression.

Table 1. Police Anti-gun Strategies, Locations, and Effectiveness.

\begin{tabular}{llll}
\hline Strategies & Locations & Evaluation \\
\hline Problem-oriented/Community-oriented & & & Effectiveness \\
Place-oriented/Targeted & Kansas & Yes & Yes \\
Place-oriented/Targeted & Indianapolis & Yes & Yes \\
Place-oriented/Targeted & Pittsburgh & No & Yes \\
Place-oriented/Targeted & New York & No & Unknown \\
Suppression/Youth-related & St. Louis & Yes & Unknown \\
Suppression/Gang-related & Boston & Yes & Yes \\
Suppression/Gang-related & Minneapolis (MN) & Yes \\
Suppression/Gang-related & Baltimore (MD) & Yes \\
\hline
\end{tabular}




\begin{tabular}{llll}
\hline Strategies & Locations & Evaluation & Effectiveness \\
\hline Suppression/Gang-related & Los Angeles (CA) & Yes & Yes \\
Suppression/Gang-related & Stockton (CA) & Yes & Yes \\
Offense Type-related & Richmond (VA) & Yes & Yes \\
Weed and Seed/Abatement & Buffalo (NY) & Yes & Yes \\
Weed and Seed/Abatement & Indianapolis (IN) & Yes & Yes \\
Weed and Seed/Abatement & Oakland (CA) & Yes & Yes \\
Situational/Environmental & & & Yes \\
Risk Terrain Modeling & Little Rock (AR) & Yes & Yes \\
Contextual/Routine Activity & Eastern City & Yes & Yes \\
\hline
\end{tabular}

The Kansas City Gun Project and its subsequent replications in Indianapolis and Pittsburgh all used placeoriented policing strategies to attempt to confiscate proscribed firearms and prevent crime in gun violence hot spots. The Kansas City Gun Project implemented proactive patrol and intensively enforced firearms laws via safety frisks during traffic stops, plain view searches and seizures, and searches incident to arrests on other charges [3]. The targeted police patrols were conducted in areas with a high homicide rate. Data from the targeted area were compared with data from a beat with nearly identical numbers of drive-by shootings in 1991. The comparison beat received routine levels of police activities. Sherman and Rogan [3] assessed the impact of hot-spot policing on firearms seizures and crime and concluded that proactive patrols focused on firearms recoveries resulted in a statistically significant increase in firearms seizures and a statistically significant decrease in firearm-related crimes in the target beat area while firearms seizures and firearm-related crimes in the comparison beat area did not change significantly.

The Indianapolis Police Department (IPD) implemented a police strategy similar to the Kansas City program [19]. The study utilized a pre-post quasi-experimental design with a non-equivalent comparison group and an interrupted timeseries design to evaluate a directed police patrol program. In one district, the IPD pursued a directed patrol/specific deterrence strategy that sought to prevent firearm-related violence by focusing on suspicious activities and locations. In the other district, the IPD pursued a general deterrence strategy that attempted to prevent firearm-related violence by maximizing the number of vehicle stops. The evaluation revealed that there were statistically significant decreases in firearm-related crime, homicide, aggravated assault with a firearm, and armed robbery in the targeted patrol district. No statistically significant changes in firearm-related crime were noted in the general patrol district [19].

The Pittsburgh Police Department focused on suppressing illegal guns on city streets through the implementation of a special Gun Suppression Patrol program [14]. Two patrol teams of four officers each were assigned to separate police zones experiencing high rates of illegal gun activity. The patrol teams focused on high-risk times and places in targeted areas and initiated citizen contacts through traffic stops and "stop and talk" activities with persons on foot. The evaluation found that shots-fired calls for service from residents were reduced by more than 50 percent in one target area, and gunshot injuries were down by nearly 70 percent in the other target area, representing a reduction of 2.5 gunshot injuries weekly in the latter target area $[9,14]$.

The New York Police Department (NYPD) maintained a special Street Crime Unit that targeted firearm-related violence hot spots and sought out sources of illegal firearms [20]. Between 1994 and 1997, the NYPD made 46,198 gun arrests and confiscated 56,081 firearms. Nonfatal shootings declined by 62 percent between 1993 and 1997 and, in 1998, New York had only 633 homicides, its lowest since 1964 [20].

St. Louis's Firearm Suppression Program (FSP) sought parental consent to search for and seize the guns of juveniles [21]. It represents a police program to prevent firearm-related violence by disarming a very risky population of potential gun offenders. The St. Louis Metropolitan Police Department's Mobile Reserve Unit initiated home searches on the basis of resident requests for police service, reports from other police units, and information gained from other investigations. A key component of the program was to respond to problems identified by residents, and the success of the program was reliant on effective police-community relationships. A rigorous impact evaluation of the program was not completed.

The Boston Gun Project dubbed Operation Ceasefire was aimed at reducing youth firearm-related violence by isolating a small number of chronically offending gang members responsible for much of Boston's youth gun violence [22, 23] [24]. Law enforcement personnel, youth workers, and researchers diagnosed the youth violence problem as a largely vendetta-like hostilities among a small population of chronic youth offenders. The Operation Ceasefire strategy was designed to deter by having police officers reach out directly to gangs, saying explicitly that violence would no longer be tolerated, and backing up that message by applying every means legally available when violence occurred [25]. Simultaneously, youth workers, probation and parole officers, and churches and other community groups offered gang members services and other kinds of help. Braga et al. [23] found that the Operation Ceasefire intervention was associated with a 63 percent decrease in monthly number of Boston youth homicides, a 32 percent decrease in monthly number of shots-fired calls, a 25 percent decrease in the monthly number of firearm-related assaults, and in one highrisk police district given special attention in the evaluation, a 44 percent decrease in monthly number of youth firearmrelated assault incidents. The Operation Ceasefire program also sought to disrupt the illegal trafficking of firearms by 
focusing local, state, and federal authorities on intrastate and interstate trafficking, on traffickers of those makes and calibers of guns most used by gang members, and through analysis of crime gun traces [23].

Minneapolis (MN), Baltimore (MD), Los Angeles (CA), Stockton (CA), and Indianapolis (IN) followed the example of Boston's Operation Ceasefire strategy to address the causes of youth gun violence. Basic pretest/posttest analyses from these initiatives revealed that these approaches to the strategic prevention of gang and group-involved violence were associated with reductions in violent crime [26-27].

The U.S. Attorney's Office in Richmond, Virginia, implemented Project Exile to deter gun violence with a focus on specific offense types [28-29]. The Southern District of Alabama's Project Safe Neighborhoods called for Federal prosecution of certain gun crimes and minimum mandatory sentences for convicted offenders [30]. The strategies of assigning a prosecutor to specialize in firearms cases and developing a case management system to track targeted cases have also been used to improve the prosecution of juvenile offenders [31].

Buffalo Weed and Seed Initiative involves the Gun Abatement Program focused on reducing the availability of guns on the street by targeting drug and weapons dealers and high-crime locations. Specific activities include door-to-door visits by police officers in targeted area, a gun report hotline, street contacts, intensive enforcement in targeted areas, and ATF gun trace of seized weapons [20]. Impact of the initiative and related activities in the system was dramatic as 15 to 20 shooting deaths occurred on average in the target area per year, and only 1 shooting death was reported in the year after the intervention. And overall index crimes in the area dropped by 31 percent in the first 9-months of the intervention compared to the same time-frame in the previous year [20]. The gun abatement strategy was also used in East Bay Corridor in Oakland, CA and Indianapolis, IN that involves the use of community policing, domestic violence protocol, hotline, gun buy-back, and monetary reward for guns seized. Other related activities include those to interrupt sources of illegal guns, to deter illegal gun possession and carrying, judicial response, and education programs. These efforts led also to a dramatic decrease in gun violence [20].

Little Rock (AR) was a site used to assess the accuracy and precision of two mapping techniques as predictors of future gun crimes: the risk terrain modelling (RTM) and nearest neighbor hierarchical (NNH). The RTM incorporates measures of environmental factors such as crime generators and crime attractors. $\mathrm{NNH}$ is a traditional hot spot technique, which relies on past crime to predict where future crime is likely to occur. Data from the Little Rock Police Department indicates that most of the social and physical environmental measures in the RTM significantly predicted future gun crime locations and the NNH hot spots predicted $7 \%$ of future gun crime. Although accuracy is a potential limitation of RTM, RTM is more reliable than hot spot technique due to the inclusion of the environmental factors [32].

Eastern City Gun Project (NJ) was a study of gun case files from a local police department focused on understanding the environmental and operational variables [15]. Hundreds of local gun cases were compiled and developed into a gun-case database for this purpose. The analysis of the database suggests that the more public an area, the fewer invalid permit and possessory offenses and more substantive offenses. Nonlocal residence correlates more with invalid permit/unlawful possession type of offenses and local residence more with substantive offenses. Local residents also resisted arrest significantly more than nonlocal residents. The worse the public security or perception of it is in a certain district, the higher chance of gun use. Special police investigations correlated more to arrests than general investigations. Cases involving more vehicles/units dispatched were associated with more arrests. Cases involving guns and drugs are more likely closed than cases involving no guns and drugs. Cases involving violent offenses remained open more often than cases involving less violent offenses.

Previous reviews and survey demonstrate that hot-spot, directed, and focused police efforts led to reduction in gun crime. Reviews by Sherman [33] and the National Research Council [17] indicate that uniformed police patrols in gun crime hot spots and background checks for gun buyers work in reducing gun crimes while gun buyback programs do not and gun ban works partially. Koper and Mayo-Wilson's review [34] of police strategies to reduce illegal possession and carrying of firearms suggests that in six of the seven test sites directed patrols reduced gun crime in high-crime places at high-risk times. A national survey of police agencies serving cities of over 100,000 people suggests that gun crime is lower in places where police engage in more intensive gunrelated enforcement and prevention efforts. Strategies used most frequently and rated as most effective include targeted efforts focused on high-risk places and groups, as well as multi-agency problem-solving efforts, particularly those involving federal authorities. However, most agencies make limited use of proactive strategies to reduce gun crime, and there are substantial gaps in the enforcement of many gun laws [35].

\section{Discussions}

Most of the studies reviewed suggest that focused police efforts have a significant effect on gun crime, namely, increased firearms seizures, reductions in gun crime, and little if any displacement [17]. Further and more systematic research on police strategies, however, is warranted to understand how these efforts really work in reducing gun violence [35]. Many of the police strategies reviewed were not studied in detail, and assessments of the effectiveness sometimes reflect the views of practitioners. There is a need for more in-depth research on gun-related enforcement and prevention practices, their effectiveness, and the organizational and environmental factors that facilitate or hinder them. Many complex factors affect the problem of gun violence and it is often difficult to specify the exact role a 
police strategy played in the reduction of gun crime. Questions remain on whether these strategies will have longterm effects on gun violence and how gun offenders will adapt to changes in police tactics [34].

Most studies reviewed suffer from methodological flaws as data used for analysis were not derived from a true experimental design [17]. Particular effects of police interventions are difficult to pinpoint due to preintervention differences between intervention and comparison areas. Researchers have to control effectively for many confounders that influence gun crime. This is difficult because researchers have to contend with the reality that police strategies are usually not randomly adopted, gun violence trends are influenced by a variety of factors, and the dynamics of gun crime are highly complex [17]. Conclusions and generalizations about police strategies therefore must be qualified based on the small number of studies and variability in study design and analysis [34].

While police can learn from previous studies about effectiveness of police strategies, types of gun crimes and violent gun crimes [36-38], gun trace [37], and types of guns $[12,13,39-41]$, they should also understand the contexts and police operations as related to gun incidents. The association between public areas and substantive crimes indicates that police should target public areas prone for gun crime not only with effective strategies but also with situational and routine activities. They need to address public perception of certain areas and create a sense of security by increasing their visibility in those areas. Special investigation should be used to increase arrests. More units should be dispatched for gun incidents to increase the chance of arrests and solving gun cases.

\section{Conclusions}

Problem-oriented policing, community policing, and situational and routine activity strategies all seem to demonstrate an effect on gun crime, whether they are placeoriented, target-oriented, offender-focused, behavior-focused, or based on environmental and operational variables. Most evaluations were able to link key components of police interventions to subsequent gun crime or individual behaviors subjected to the interventions. Previous reviews of gun studies and national survey also show that directed/targeted strategies against gun crimes work.

The amount of research and knowledge on police strategies against gun crime remains rather limited. Although many police strategies reviewed seem to be effective in reducing gun violence, they were implemented as new interventions, subject to funding availability, and their effects may be transient and cannot always be explained by police interventions alone as many confounding factors remain elusive. Available studies also rarely address the immediate environment of gun incidents and routine police activities related to gun crimes. The situational crime prevention perspective focused on environmental factors and routine activities rather than temporary police tactics seems underutilized in understanding the police role in reducing gun violence. The dynamics of gun incidents and response effectiveness as influenced by the immediate environment and routine police activities need to be studied further.

\section{References}

[1] Goldstein, H. (1990). Problem-Oriented Policing. Philadelphia: Temple University Press.

[2] Eck, J. E., and Spelman, W. (1987). Problem-Solving: Problem-Oriented Policing in Newport News. National Institute of Justice. Washington, DC: U.S. Department of Justice.

[3] Sherman, Lawrence W.; Shaw, James W.; and Rogan, Dennis P. (1995). The Kansas City Gun Experiment. Research in Brief. Washington: National Institute of Justice.

[4] Wolfgang, M., Figlio, R., and Sellin, T. (1972). Delinquency in a Birth Cohort. Chicago: University of Chicago Press.

[5] Rolph, J., Chaiken, J., and Houchens, R. (1981). Methods for Estimating the Crime Rates of Individuals. Santa Monica, CA: RAND Corporation.

[6] Clarke, Ronald V. (1992). Situational Crime Prevention: Successful Case Studies. Albany, NY: Harrow and Heston. Pages, 4, 5, and 8.

[7] Brantingham, P. J. and Brantingham, P. L. (1991). Environmental Criminology. ( $2^{\text {nd }}$ Ed.). Prospect Heights, IL: Waveland Press. Page 239.

[8] Mayhew, P., Clarke, R. V., Sturman, A. and Hough, J. M. (1976). Crime as Opportunity. London: HMSO.

[9] Bureau of Alcohol, Tobacco, and Firearms (BATF). (2002). Firearms Commerce in the United States 2001-2002. Washington, DC: U.S. Department of the Treasury.

[10] Kaplan, Fred. (1999). Jury Finds Gun Firms Negligent. The Boston Globe, February 12.

[11] Sugarmann, J. and Rand, K. (1994). Cease Fire: A Comprehensive Strategy to Reduce Firearms Violence. Washington, D. C.: Violence Policy Center.

[12] Cook, Philip J. and Ludwig, Jens. (1997). Guns in America: National Survey on Private Ownership and Use of Firearms. Research in Brief. Washington, D. C.: National Institute of Justice.

[13] Zawitz, Marianne W. (1995). Firearms, Crime, and Criminal Justice: Guns Used in Crime. Bureau of Justice Statistics Selected Findings. Washington, D. C.: Bureau of Justice Statistics, U.S. Department of Justice.

[14] Cohen, Jacqueline and Ludwig, Jens. (2003). Policing Crime Guns. Pp. 217-239 in Evaluating Gun Policy: Effects on Crime and Violence, edited by Jens Ludwig and Philip J. Cook. Washington, D. C.: Brookings Institution Press.

[15] Jiao, Allan Y. (2014). The Eastern City Gun Project: Exploring Contextual and Operational Variables. Journal of Police \& Criminal Psychology, 29(1), pp. 10-21. 
[16] Meyer, B. D. (1995). Natural and quasi-experiments in economics. Journal of Business and Economic Statistics 13(2):151-162.

[17] National Research Council. (2005). Firearms and Violence: A Critical Review. Committee to Improve Research Information and Data on Firearms. Charles F. Wellford, John V. Pepper, and Carol V. Petrie, editors. Committee on Law and Justice, Division of Behavioral and Social Sciences and Education. Washington, DC: The National Academies Press.

[18] Carter, Gregg Lee. (2006). Gun Control in the United States: A Reference Handbook. Denver, Colorado: ABC-CLIO.

[19] McGarrell, Edmund F; Chermak, Steven; Weiss, Alexander; Wilson, Jeremy. (2001). Reducing firearms violence through directed police patrol. Criminology \& Public Policy, 1(1), pp. 119-148.

[20] Office of Juvenile Justice and Delinquency Prevention (OJJDP). (1999). Promising Strategies to Reduce Gun Violence. OJJDP Report. Washington, D. C.: Office of Justice Programs, U.S. Department of Justice.

[21] Rosenfeld, R., and Decker, S. (1996). Consent to search and seize: Evaluating an innovative youth firearms suppression program. Law and Contemporary Problems 59(2):197-220.

[22] Allis, Sam. (1997). How to Start a Ceasefire: Learning from Boston. Time, July 21, 150(3).

[23] Braga, Anthony A.; Kennedy, David M.; Waring, Elin J.; and Piehl, Anne Morrison. (2001). Problem-Oriented Policing, Deterrence, and Youth Violence: An Evaluation of Boston's Operation Ceasefire. Journal of Research in Crime and Delinquency, 38(3): 195-225.

[24] Kennedy, David M.; Braga, Anthony A.; Piehl, Anne M.; and Waring, Elin J. (2001). Reducing Gun Violence: The Boston Gun Project. Washington, D. C.: National Institute of Justice.

[25] Kennedy, D. M. (1997). Pulling levers: Chronic offenders, high-crime setting and a theory of prevention. Valparaiso University Law Review 31(2):449-484.

[26] Braga, A. A., Cook, P. J., Kennedy, D. M., and Moore, M. H. (2002). The illegal supply of firearms. In M. Tonry, ed., Crime and Justice: A Review of Research. Volume 29. Chicago: University of Chicago Press.

[27] Tita, George E.; Riley, K. Jack; Ridgeway, Greg; and Greenwood, Peter W. (2005). Reducing Gun Violence: Operation Ceasefire in Los Angeles. Washington, D. C.: Office of Justice Programs, National Institute of Justice.

[28] Payne, Brian K., and Gainey, Randy R. (2008). Guns, Offense Type, and Virginia Exile: Should Gun Reduction Policies Focus on Specific Offenses? Criminal Justice Policy Review, 19(2):181-195.

[29] Raphael, Steven and Ludwig, Jens. (2003). Prison Sentence
Enhancements: The Case of Project Exile. Pp. 251-276 in Evaluating Gun Policy: Effects on Crime and Violence, edited by Jens Ludwig and Philip J. Cook. Washington, D. C.: Brookings Institution Press.

[30] O'Shea, Timothy C. (2007). Getting the Deterrence Message Out: The Project Safe Neighborhoods Public-Private Partnership. Police Quarterly, 10(3):288-307.

[31] Scales B., and Baker J. (2000). Seattle's effective strategy for prosecuting juvenile firearm offenders. Washington, D. C.: U.S. Department of Justice,

[32] Drawve, Grant; Moak, Stacy C.; and Berthelot, Emily R. (2014). Predictability of gun crimes: a comparison of hot spot and risk terrain modelling techniques. Policing and Society: An International Journal of Research and Policy, 26(3), Pp. 312-331.

[33] Sherman, Lawrence W. (2001). Reducing Gun Violence: What Works, What Doesn't, What's Promising. Criminal Justice; 1(1):11-25.

[34] Koper, Christopher and Mayo-Wilson, Evan. (2006). Police crackdowns on illegal gun carrying: a systematic review of their impact on gun crime. Journal of Experimental Criminology, 2, pp. 227-261.

[35] Koper, Christopher S.; Woods, Daniel J.; and Kubu, Bruce E. (2013). Gun violence prevention practices among local police in the United States. Policing: An International Journal of Police Strategies \& Management, 36(3), pp. 577-603.

[36] Kennedy, D. M.; Piehl, A. M.; and Braga, A. A. (1996). Youth Gun violence in Boston: Gun markets, serious youth offenders, and a use reduction strategy. Law and Contemporary Problems, 59:147-196.

[37] Pierce, G. L.; Briggs, L.; and Carlson, D. A. (1996). The identification of patterns in firearms trafficking: Implications for focused enforcement strategies. Washington, DC: Department of Treasury.

[38] Scalia, John. (2000). Federal Firearm Offenders, 1992-98. Bureau of Justice Statistics Special Report. Washington, D. C.: Office of Justice Program, Bureau of Justice Statistics, U.S. Department of Justice.

[39] Harlow, Caroline Wolf. (2001). Firearm Use by Offenders: Survey of Inmates in State and Federal Correctional Facilities. Washington, D. C.: Bureau of Justice Statistics.

[40] Ruddell, R. (2000). Using the NIJ threat level scale to evaluate the capacity for lethality of juvenile firearm. Paper presented at the Midwestern Criminal Justice Association annual meeting, Chicago, October.

[41] Ruddle, Rick and Mays, G. Larry. (2003). Examining the Arsenal of Juvenile Gunslingers: Trends and Policy Implications. Crime and Delinquency; 49(2):231-252. 